\title{
The importance of elbow aspiration when treating radial head fractures
}

\author{
J. F. DOOLEY \& P. D. ANGUS
}

Rayne Institute, St Thomas' Hospital, London and Dewsbury General Hospital, Dewsbury, West Yorkshire

\section{SUMMARY}

A prospective study of elbow aspiration was performed to assess the effect of this procedure on pain relief and function following Type I and II fractures of the radial head.

Aspiration of the haemarthrosis produced dramatic pain relief in $77 \%$ of elbows thus treated. Earlier return of function was also noted for these elbows compared to controls. We recommend elbow aspiration for patients with these fractures to both relieve pain and restore early function.

\section{INTRODUCTION}

Fractures of the radial head are commonly seen in the Accident and Emergency Department resulting from either direct injury to the elbow or secondary to a fall upon the outstretched hand. Mason (1954) classified these fractures into Type I undisplaced, Type II - minimally displaced and Type III - comminuted fractures of the whole head of the radius. The principle of early surgical intervention for management of Type III fractures is well established.

Management of the other types of fractures of the radial head is less well defined. Standard texts advocate mobilization from a sling or plaster either immediately or following a period of rest (Adams, 1972 Watson-Jones, 1982). Reports in the orthopaedic literature have suggested that pain relief and early return of function may be achieved by aspiration of the haemarthrosis which accumulates in the elbow joint following this fracture (Post Lethwaite, 1945; Gaston et al., 1949; Quigley, 1949). This management is accepted practice for haemarthrosis in other joints. This study presents a prospective trial of management comparing Type I and II radial head fractures in a control group of patients treated by rest then mobilisation with a group treated by aspiration of the elbow haemarthrosis and

Correspondence: J. F. Dooley FRCS FRCS, Rayne Institute, St Thomas' Hospital, London, U.K. 
mobilization, to assess the effect of elbow aspiration upon pain relief and return of function.

\section{METHOD}

Over an 18-month-period all patients presenting to the Accident and Emergency Department with radiologically confirmed Types I and II fractures of the radial head were randomly allocated to one of the treatment groups. All patients were seen by one of the authors within $72 \mathrm{~h}$ of injury. Details of age, sex and mechanism of injury were noted. Forearm rotation and elbow movement were assessed using a goniometer. Patients were asked to grade their pain as severe, moderate, mild or absent.

The elbows of the trial group were then aspirated. This was performed in the outpatient department using standard aseptic technique. Aspiration of the elbow joint was done through the posterolateral approach described by Gaston (1949). The needle is introduced through the midpoint of the triangle bordered by the olecranon, radial head and lateral humeral epicondyle. No local anaesthetic was necessary as no patient found the procedure unduly uncomfortable. No elbows required repeat aspiration. After aspiration the elbow was reassessed and the patients again asked to grade their pain. Patients in both groups were fitted with a collar and cuff but were referred to physiotherapy who applied ice to the elbows and encouraged active movement of the elbow as pain permitted. They were seep at follow up clinics at approximately 3, 6 and 12 weeks, 6 months and 12 month after injury. The range of movement and degree of pain was recorded at each attendance.

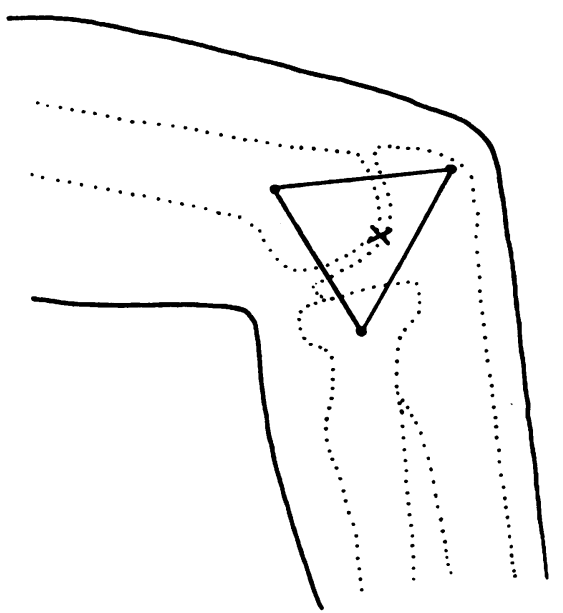

Fig. 1 Line drawing to demonstrate the point of needle insertion for aspiration of elbow haemarthrosis 


\section{RESULTS}

Twenty-eight patients were included in the study, 13 of these elbows were aspirated and form the trial group. Fifteen elbows were not aspirated and form the control group. There were 15 men and 13 women. The average age of the control group was 40 (range 18-57) years and in the trial group 32 (range 16-63) years. Three patients in the trial group had a concomitant ipsilateral scaphoid fracture. The injury resulted from a direct blow in 14 patients, a fall on to the outstretched hand in 12, and 2 patients were uncertain of the mechanism of their injury.

The control group contained 5 Type I and 10 Type II fractures. The trial group consisted of 6 Type I and 7 Type II fractures. An average of 8 millilitres (range $4-20 \mathrm{ml}$ ) of blood stained fluid was aspirated.

The average loss of each component of elbow movement in each group during the first 6 weeks after injury is shown in Table I. It shows that aspiration of the haemarthrosis in the trial group produced an increase in the range of all elbow movements.

At 3 and 6 weeks after injury the average loss of movement was less in the trial than the control group (Table I). At 6 weeks following injury $62 \%$ of patients in the trial group had a full range of movement compared to $28 \%$ in the control group.

Table 1 Average loss of movement vs. time after injury

\begin{tabular}{|c|c|c|c|c|c|}
\hline \multirow[b]{2}{*}{ Time } & \multirow[b]{2}{*}{ Group } & \multirow[b]{2}{*}{ Flexion } & \multicolumn{2}{|c|}{ Average loss in degrees } & \multirow[b]{2}{*}{ Supination } \\
\hline & & & Extension & Pronation & \\
\hline \multirow[t]{3}{*}{ At injury } & control & 30 & 45 & 21 & 25 \\
\hline & Trial - Pre-Aspiration & 20 & 66 & 20 & 31 \\
\hline & Trial - Post-Aspiration & 12 & 11 & 8 & 0 \\
\hline \multirow{2}{*}{ Three weeks } & control & 12 & 28 & 3 & 2 \\
\hline & Trial & 6 & 9 & 0 & 0 \\
\hline \multirow[t]{2}{*}{ Six weeks } & control & 6 & 15 & 0 & 0 \\
\hline & Trial & 4 & 5 & 0 & $\mathbf{0}$ \\
\hline
\end{tabular}

Table 2 Patients who had not gained full range by 6 months

\begin{tabular}{lc}
\hline Group & Loss of Movement \\
\hline Control & 1 patient lacked 50 degrees extension \\
& 25 degrees pronation \\
& 1 patient lacked 35 degrees extension \\
& 1 patient lacked 10 degrees extension \\
& 20 degrees supination \\
& 1 patient lacked 30 degrees extension \\
& 30 degrees pronation \\
& 1 patient lacked 5 degrees extension \\
\hline
\end{tabular}


Table 3 Level of pain vs time after injury

\begin{tabular}{|c|c|c|c|c|c|c|c|}
\hline & \multirow[b]{2}{*}{ Presentation } & \multirow[b]{2}{*}{$\begin{array}{c}\text { After } \\
\text { Aspiration }\end{array}$} & \multicolumn{2}{|c|}{ Trial Group } & \multicolumn{3}{|c|}{ Control Group } \\
\hline & & & 3 weeks & 6 weeks & Presentation & 3 weeks & 6 weeks \\
\hline Severe & 4 & 0 & 0 & 0 & 4 & 0 & 0 \\
\hline Moderate & 9 & 0 & 0 & 0 & 9 & 5 & 2 \\
\hline Mild & 0 & 6 & 3 & 2 & 2 & 8 & 7 \\
\hline None & 0 & 7 & 10 & 11 & 0 & 2 & 6 \\
\hline
\end{tabular}

At 6-month follow-up 3 patients in the control and 2 patients in the trial groups $\vec{\omega}$ lacked a full range of movement. Their details are shown in Table II. All 5 were Type II fractures, 1 of the 2 trial patients had an ipsilateral scaphoid fracture.

Details of patients pain are shown in Table III. It shows that aspiration of the elbow joint haemarthrosis brings about a dramatic reduction in patients pain. Tenof the 13 trial patients $(77 \%)$ reported instant relief of pain in their elbows following this procedure. At the 6-week follow-up the pain levels in the trial

group were still considerably better than the controls.
At 1-year follow-up 2 patients in each group lacked a full range of elbow extension. Two patients in the control group and 1 in the trial group were unable $\overrightarrow{0}$ to carry heavy weights because of pain in the elbow. All other patients in botho groups had pain free function.

\section{DISCUSSION}

The treatment of Type I and Type II radial head fractures advocated by standard $\overrightarrow{\overrightarrow{0}}$ orthopaedic textbooks consist of a period of rest - either with or without plaster of Paris immobilization - followed by gradual mobilization. The elbows in this study were mobilised as soon as pain permitted. In a study reported by Radin \& Riseborough (1966) it was found that early mobilization of the elbow resulted in 3 further displacement of the radial head fragment. They suggested that this was responsible for a poor outcome in some of their patients. However, the results of ao study by Bakalim (1970) showed that displacement of the fragment was not associated with loss of function. Furthermore Mason and Shutkin (1943) have suggestedo that early mobilization allows the fragment to attain the best functional position in relation to the other joint surfaces. In our study the elbows with a poor outcome? all had Type II fractures suggesting a poorer prognosis in fractures with greater $\tilde{O}$ initial displacement. This reflects the severity of the initial injury in relation ton outcome rather than further displacement following mobilization. Our result ज్ support those of Holdsworth et al., (1987) that delay in movement delayed recovery of function.

Aspiration of the elbow joint as part of the treatment of these fractures has been advocated by many authors in the past (Gaston et al., 1969; Pastlethwaite, 1945, Quigley, 1949). They found that the procedure relieved pain and allowed earlyo 
return of function. Other trials of aspiration of the elbow in these fractures have been reported in the literature. In 1949 Gaston (1949) reported that aspiration gave early relief of pain. In his study, at thirty days after injury, $76 \%$ of the elbows which had been aspirated had regained a full range of movement compared to only $44 \%$ of those which had not been aspirated. He reported no difference between the two groups at 20 months follow up. Fleetcroft (1984) reported a prospective study with a 2 year follow up. He found that the patients in the aspirated group had earlier relief of pain and greatly enhanced return of function, and he also found a significant difference between the two groups at the long term follow up. Of the elbows in this study with Type I fractures $17 \%$ of those which were not aspirated lacked a full range of movement. Of the elbows with Type II fractures $56 \%$ of those aspirated compared with $77 \%$ of those which were not aspirated lacked a full range of movement. Our results support those of Holdswoth et al. (1987) who showed that delay in restoration of early active movement led to a delay in recovery of function.

The results of this study have shown that aspiration of the elbow produces early and dramatic relief of pain and an earlier improvement in the range of movement in the elbow. They do not show the sustained impairment of movement in the non-aspirated elbows at final follow up which occurred in Fleetcroft's study. We would agree with Holdsworth et al.'s (1987) comments that this probably relates to a delay in recommencing active movement. We would recommend aspiration of the elbow as part of the treatment of Type I and II radial head fractures. It is a quick, safe, and painless procedure which greatly reduces the patient's discomfort and allows an early return of movement of the elbow.

\section{REFERENCES}

Adams J. C. (1972) Outline of Fractures. Churchill Livingstone, Edinburgh and London pp. 7.

Bakalim G. (1970) Fractures of the Radial Head and their Treatment. Acta Orthopaedica Scandinavica 41, 320-331.

Fleetcroft J. P. (1984) Fractures of the Radial Head. Early Aspiration and Mobilization. Journal of Bone and Joint Surgery 66B, 141-142.

Gaston S. R., Smith F. M \& Baab O. D. (1949) Adult Injuries of the Radial Head and Neck. American Journal of Surgery 78, 631-635.

Holdsworth B. J., Clement D. A. \& Rothwell P. N. R. (1987) Fractures of the radial head - the benefit of aspiration: A prospective controlled trial. Injury 18, 44-47.

Mason J. A. \& Shutkin N. M. (1943) Immediate Active Motion in the Treatment of Fractures of the Head and Neck of the Radius with a review of one hundred cases. Surgery, Gynecology and Obstetrics 76, 731-737.

Mason M. L. (1954) Some observations on Fracture of the Head of the Radius. British Journal of Surgery 42, 123-132.

Postlethwaite R. W. (1945) Modified treatment of Fractures of the Head of the Radius American Journal of Surgery 67, 77-80.

Quigley J. B. Aspiration of the Elbow Joint in the Treatment of Fractures of the Head of the Radius. New England Journal of Medicine 240, 915-916.

Radin E. L. \& Riseborough E. J. (1966) Fractures of the Radial Head Journal of Bone and Joint Surgery 48A, 1055-1064.

Watson-Jones R. (1982) Fractures and Joint Injuries (Ed. J. N. Wilson) Churchill Livingstone. Edinburgh and London. 